\title{
NOTE \\ Molecular epidemiological survey and phylogenetic analysis of bovine respiratory coronavirus in Japan from 2016 to 2018
}

\author{
Hirohisa MEKATA ${ }^{1,2) *}$, Saori HAMABE ${ }^{3)}$, Putu Eka SUDARYATMA ${ }^{3)}$, \\ Ikuo KOBAYASH ${ }^{4)}$, Toru KANNO ${ }^{5}$ and Tamaki OKABAYASHI ${ }^{2,3)}$
1)Organization for Promotion of Tenure Track, University of Miyazaki, Miyazaki 889-2192, Japan
${ }^{2)}$ Center for Animal Disease Control, University of Miyazaki, Miyazaki 889-2192, Japan
4)Field Science Center, Faculty of Agriculture, University of Miyazaki, Miyazaki 880-0121, Japan
${ }^{5)}$ Hokkaido Research Station, National Institute of Animal Health, National Agriculture and Food Research Organization, Sapporo, Hokkaido 062-0045, Japan \\ ${ }^{3)}$ Department of Veterinary Sciences, Faculty of Agriculture, University of Miyazaki, Miyazaki 889-2192, Japan
}

J. Vet. Med. Sci.

82(6): $726-730,2020$

doi: 10.1292/jvms.19-0587

Received: 28 October 2019

Accepted: 1 April 2020

Advanced Epub:

9 April 2020
ABSTRACT. Bovine coronavirus (BCoV) is an etiological agent of bovine respiratory disease (BRD). $B R D$ is a costly illness worldwide; thus, epidemiological surveys of BCoV are important. Here, we conducted a molecular epidemiological survey of $\mathrm{BCoV}$ in respiratory-diseased and healthy cattle in Japan from 2016 to 2018 . We found that 21.2\% (58/273) of the respiratory-diseased cattle were infected with $\mathrm{BCoV}$. The respiratory-diseased cattle had virus amounts 4.7 times higher than those in the asymptomatic cattle. Phylogenetic analyses showed that the BCoV identified in Japan after 2005 formed an individual lineage that was distinct from the strains found in other countries. These results suggest that $\mathrm{BCoV}$ is epidemic and has evolved uniquely in Japan.

KEY WORDS: bovine respiratory coronavirus, bovine respiratory disease, individual lineage, Japan, viral load

Bovine respiratory disease (BRD) is one of the most common and costly diseases in the cattle industry worldwide. Some viruses and bacteria, such as bovine respiratory syncytial virus, bovine herpesvirus 1, Mycoplasma bovis and Pasteurella multocida, are etiological agents of BRD [7]. Although many cases of single virus or bacterial infection cause mild-to-moderate symptoms, coinfection with several microbes is associated with severe pneumonia [20,21]. Therefore, it is important to monitor and identify pathogens that are related to BRD.

Bovine coronavirus (BCoV) belongs to the family Coronavirus, genus Betacoronavirus, species Betacoronavirus 1, which includes porcine hemagglutinating encephalomyelitis virus and equine coronavirus. BCoV has been associated with mild-to-bloody diarrhea in neonatal calves and adult cattle [6,22]. Recent metagenomic and multiplex studies showed that this virus has also been identified as a major contributor to BRD $[18,19,24]$. Thus, control of $\mathrm{BCoV}$ infection may decrease the incidence of BRD. Betacoronavirus 1 is composed of five structural proteins: a nucleocapsid $(\mathrm{N})$, a membrane $(\mathrm{M})$, a spike (S), an envelope (E) and a hemagglutinin esterase (HE). The S protein forms petal-shaped spikes on the surface of the virion and has been associated with antigenicity [23]. The $\mathrm{S}$ gene includes a polymorphic region, and its sequence is useful for the genetic classification of the virus [2, 9].

The extent of the contribution of BCoV to BRD cases in Japan is unclear, and a large-scale molecular survey has not been conducted in the last decade [12]. In this study, we compared the health condition of cattle with the infection rate and viral copy number of $\mathrm{BCoV}$ to determine its influence on BRD. Furthermore, we performed phylogenetic analyses of the polymorphic region of the $\mathrm{S}$ gene in BCoV identified in Japan from 2016 to 2018 to clarify the genetic changes and entry routes of recent strains. We believe that this study will contribute to the understanding of BCoV and decrease BRD cases in Japan.

Nasal swab samples were collected from a total of 182 healthy and 273 respiratory-diseased cattle from 42 farms in the Aichi (7 farms: $n=30$ ), Mie (11 farms: $n=106$ ), Kagoshima (4 farms: $n=36)$, Kumamoto (2 farms: $n=30$ ) and Miyazaki (18 farms: $n=253$ ) prefectures in Japan from January 2016 to February 2018. All of the sampled farms had at least one or more respiratory-diseased subjects. Because BRD outbreaks concentrate in the cold seasons, most of the samples $(371 / 455,81.0 \%)$ were collected from November to April (November: $n=13$, December: $n=40$, January: $n=116$, February: $n=106$, March: $n=47$, April: $n=49$ ). The rest of the samples were collected in the following months: May, $n=8$; July, $n=6$; August, $n=15$; September, $n=24$; and October, $n=31$. The samples were mainly collected from cattle in breeding farms (Holstein: $n=3$, Japanese Black: $n=372$, cross-breed: $n=13$, unknown: 
$n=2)$ and partly in fattening (Japanese Black: $n=40)$ and dairy (Holstein: $n=25)$ farms. The samples were mainly collected from calves ( $<6$ months old: $n=298,7-12$ months old: $n=110,>12$ months old: $n=41$, unknown: $n=6$ ). Clinical veterinarians performed the diagnoses in the cattle with respiratory disease and collected nasal swabs from the diseased and healthy cattle in the same pen. The swabs were placed in a tube containing $3 \mathrm{~m} l$ of Dulbecco's Modified Eagle's Medium (Nacalai Tesque, Kyoto, Japan) or phosphate-buffered saline supplemented with penicillin and streptomycin, and were then shipped refrigerated. All the samples were stored at $-80^{\circ} \mathrm{C}$ until further analysis. Data regarding other viruses and bacterial infections typically involved in BRD were unavailable in this study.

The methods of RNA extraction, cDNA conversion, and real-time PCR followed those in our previous report [17]. The method of generating standard curves using real-time PCR was described in our previous report [15]. The specific primers and probe sequences of $\mathrm{BCoV}$ were designed based on a previous report [13]. Their sequences were as follows: forward primer: 5'-GGACCCAAGTAGCGATGAG-3'; reverse primer: 5'-GACCTTCCTGAGCCTTCAATA-3'; and probe: 5'-FAM/ATTCCGACT/ Zen/AGGTTTCCGCCTGG/IBFQ-3'.

The sequences of the polymorphic region of the BCoV S gene corresponding to positions 25,006-25,416 of the Kakegawa strain (Accession No. AB354579) were obtained. The methods of PCR amplification, purification, and sequencing followed those in our previous report [16]. Primers for SL1 (5'-GCAGGTTTAATCCTTCTACTTGGA-3') and SR2 (5'-CACCAAGAATTATGTCTGTGTTTGA- 3') were used to amplify the target sequence [9]. When the expected size of the DNA band was weak or invisible, nested PCR was performed using the following primers with the same PCR conditions: SL1 nested (5'-CTTGGAATAGGAGATTTGGTTTT-3'), and SR2 nested (5'-CAAAAATATTACACCTATCCCCTTG-3). The sequences that were determined in this study were submitted to the DNA Databank of Japan (DDBJ) under Accession No. LC504662-730. These sequences and the available sequences that we retrieved from GenBank were aligned using ClustalW. The molecular phylogenetic trees were constructed using the neighbor-joining method with MEGA7 software [14]. The evolutionary distances were computed using Kimura's two-parameter model. A total of 1,000 bootstrap replicates were used to derive the trees based on the nucleotide sequences.

The Fisher exact test and $\chi^{2}$ test were used to compare the infection rate of $\mathrm{BCoV}$ between healthy cattle and cattle with respiratory symptoms and among age of cattle, respectively. Because of the non-normal distribution of the viral loads, the MannWhitney $U$ test was used to compare the viral loads between healthy cattle and cattle with respiratory symptoms, and respiratorydiseased cattle with and without diarrhea. These analyses were performed using GraphPad Prism 6 software (GraphPad Software, La Jolla, CA, USA). $P<0.05$ was considered statistically significant in this study.

Nineteen (Aichi: $n=3$, Kumamoto: $n=2$, Mie: $n=4$, Miyazaki: $n=10)$ of the $42(45.2 \%)$ farms positive for BRD presented at least one or more $\mathrm{BCoV}$ infection. The positive number and infection rate of each prefecture were as follows: Aichi $(n=7,23.3 \%), \mathrm{Kumamoto}$ $(n=11,36.7 \%)$, Mie $(n=15,14.2 \%)$, Miyazaki $(n=52,20.6 \%)$ and Kagoshima $(n=0,0 \%)$. The regional difference in the infection rate will not be discussed because of the deviation in the number of samples and sampling seasons. Fifty-eight of the $273(21.2 \%)$ cattle with respiratory symptoms were qPCR-positive for BCoV (Fig. 1a). On the other hand, 27 of the 182 (14.8\%) healthy cattle were also positive. Although there was no significant difference, the positive rate of cattle with respiratory symptoms was higher than that of healthy cattle $(P=0.11$, Fisher exact test). The positive rate in cattle with respiratory symptoms was similar to that in a previous study conducted in Ireland (22.9\%) [19]. The study reported that BCoV was the most frequently detected virus in calves with respiratory symptoms. Therefore, $\mathrm{BCoV}$ was epidemic and contributed to BRD outbreaks in Japan, similar to the situation in other countries. The median (average) values of viral loads in cattle with respiratory symptoms and healthy cattle were 206.0 (5691.7) and 43.6 (886.3) copies $/ \mu l$, respectively (Fig. 1b). Although there was no significant difference, the viral loads in cattle with respiratory symptoms were higher than those in the healthy cattle ( $P=0.07$, Mann-Whitney $U$ test). Our failure to identify a significant association

(a)

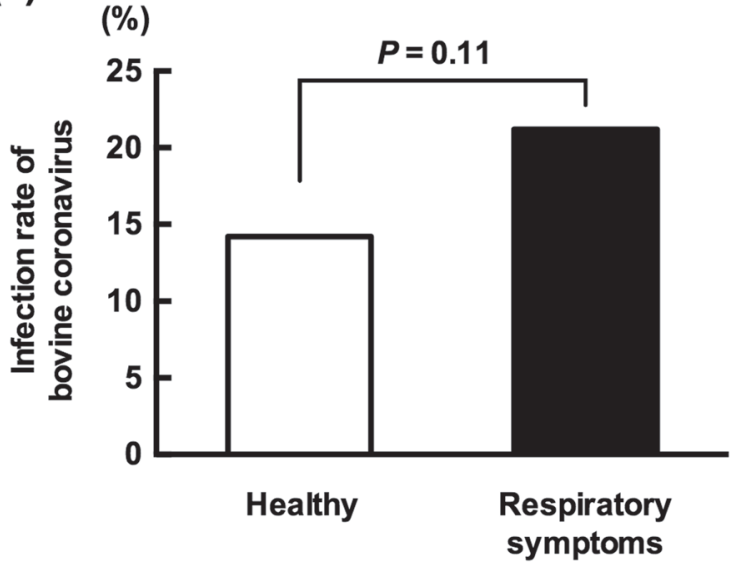

(b)

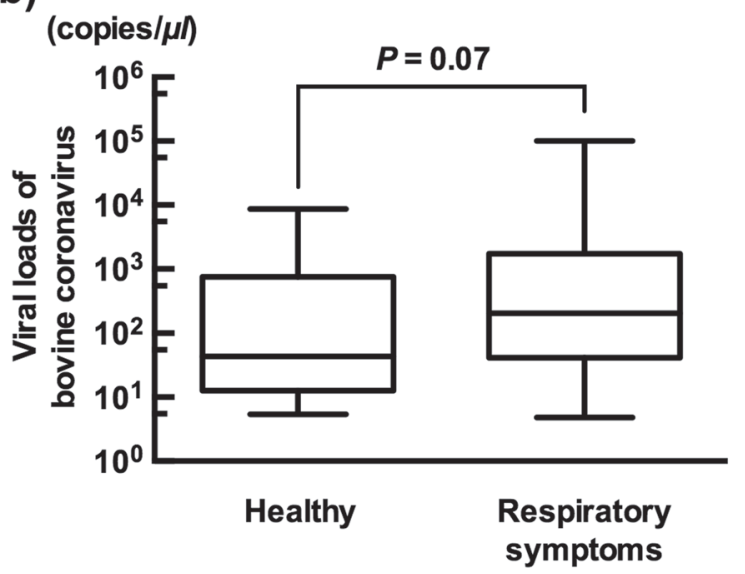

Fig. 1. The correlation between cattle with respiratory symptoms and BCoV infection. (a) The rate of BCoV infection was higher in respiratorydiseased cattle $(21.2 \%)$ than in healthy cattle (14.8\%). (b) The median value of BCoV viral loads in respiratory-diseased cattle was 4.7 times higher than that in healthy infected cattle (206.0 vs. 43.6). 
Table 1. Seasonal difference of bovine coronavirus infection rate

\begin{tabular}{lcc}
\hline \multirow{2}{*}{ Season (Month) } & \multicolumn{2}{c}{$\begin{array}{c}\text { Positive rate of bovine coronavirus } \\
\text { (No. of positive/No. of inspections) }\end{array}$} \\
\cline { 2 - 3 } & All cattle & Respiratory symptoms \\
\hline Early spring (Mar.) & $36.2 \%(17 / 47)$ & $50.0 \%(8 / 16)$ \\
Late spring (Apr., May) & $5.2 \%(3 / 57)$ & $6.6 \%(3 / 45)$ \\
Summer (Jun., Jul., Aug.) & $4.7 \%(1 / 21)$ & $4.7 \%(1 / 21)$ \\
Early autumn (Sep., Oct.) & $1.8 \%(1 / 55)$ & $2.0 \%(1 / 49)$ \\
Late autumn (Nov.) & $100 \%(13 / 13)$ & $100 \%(6 / 6)$ \\
Winter (Dec., Jan., Feb.) & $19.0 \%(50 / 262)$ & $28.6 \%(39 / 136)$ \\
\hline Total & $18.6 \%(85 / 455)$ & $21.2 \%(58 / 273)$ \\
\hline
\end{tabular}

between viral load and respiratory symptoms may be because nasal samples were not collected multiple times. For example, cattle newly infected with BCoV but not yet presenting respiratory symptoms were diagnosed as healthy in this study. Therefore, follow-up examinations should be performed to accurately reflect the correlation between viral loads and respiratory symptoms. Thirty-two of $58 \mathrm{BCoV}$-infected cattle with respiratory symptoms also had mild-to-bloody diarrhea. The median (average) values of viral loads in respiratory-diseased cattle with and without diarrhea were $271.9(6,619.3)$ and $104.0(4,550.1)$ copies/ $\mu l$, respectively. There was no significant difference $(P=0.34$, Mann-Whitney $U$ test $)$. The presence or absence of difference between bovine respiratory and enteric coronaviruses has been a controversial issue. Some of the candidate genes were reported to be the molecular determinant of tissue tropism to respiratory or intestine cells [3]. At present, consensus has yet to be reached. In this study, some calves in a farm developed only respiratory symptoms. However, the other calves in the same farm developed both respiratory and enteric diseases. The virus seemed to be from the same strain based on the partial sequence of the S gene. Therefore, the host factor, especially the existence of neutralizing antibody, may be the importance of developing diarrhea. The details about the history of BCoV-infection and vaccination were unknown in this study. Further studies are required to reveal this issue. Seventy-seven of the 85 (90.5\%) BCoV-positive cattle were under 6 months old, and the rest of the positive cattle ranged from 7 to 11 months old. No positive cattle were more than 12 months old $(n=41)$. The infection rates of cattle with less than 6 months old, 7 to 11 months old and more than 12 months old were $25.8 \%$ (77/298), 7.2\% (8/110) and $0 \%(0 / 41)$, respectively $\left(P<0.0001, \chi^{2}\right.$ test). Cattle with more than 12 months old might have neutralizing antibody acquired by $\mathrm{BCoV}$-infection in the past or vaccination, and it might inhibit the BCoV-infection in adult cattle. Castles et al. reported that the infection rate of calves born to vaccinated dams was significantly lower than that of calves born to unvaccinated dams [2]. Another study reported that calves with high neutralizing antibodies acquired through passive immunity were mostly protected against $\mathrm{BCoV}$ infection [1]. Therefore, dam vaccination is an important procedure to protect the herd from epidemic BCoV. Monovalent and combined inactivated vaccines were available for preventing BCoV infection in Japan. No sampling cattle were vaccinated by the monovalent one. On the other hand, some dams were unclear for the use of combined vaccine because of movement through the livestock market. Therefore, the vaccination history will not be discussed in this study. The percentages of detection rates by season are summarized in Table 1 . BCoV infection was most commonly detected from late autumn to early spring (November to March). This trend was similar to those in other studies [2, 19]. An experimental infection showed that BCoV persistently infects the respiratory tissues of cattle [11]. Although the mechanism of viral reactivation is unclear, cold exposure may decrease innate immunity mechanisms, such as nasal mucus velocity [4]. Coronaviruses are more stable at lower temperatures than at higher temperatures $[5,8]$. These results indicate that cold seasons may increase the risk of BCoV infection. Thus, improvement of health condition and the vaccination before the winter season might be important to prevent an epidemic of BCoV. Feeding style such as tie or free stall affects efficiency of viral transmission. In recent years, many farms in Japan changed the feeding style from tie to free stall because of upsizing the number of heads and animal welfare. Thus, it may affect the prevalence of BRD related viruses and bacteria.

The polymorphic region of the BCoV S gene was successfully amplified in 69 of the 85 qPCR-positive samples. Because of the very low copy number, the remaining 16 samples were unsuccessfully amplified. All of the strains identified in this study were classified into the Japan G4 group (Fig. 2a). Although the genetic divergence in the polymorphic region of the S gene has progressed over the last decade, no novel group was epidemic [9]. The Japan G4 groups were estimated to have entered Japan before 2005. We compared the sequences with $\mathrm{BCoV}$ isolates from around the world to estimate the entry route (Fig. 2b). The BCoVs were classified into six lineages: Europe, South America I and II, Asia and USA I and II, and Japan G4. Japan G4 was obviously independent from the other lineages, and no virus registered in GenBank, except for the Japanese strain, was classified into the Japan G4 group. Therefore, we consider Japan G4 as a Japan lineage. Few live cattle have been exported from and imported into Japan, except for importation from Australia, in the last two decades. This policy might account for the unique development of BCoV in Japan. The amino acid identities in the S polymorphic region between Japan G4 and the 66/H (Accession No. AB451543) available vaccine strain in Japan was $89 \%$ to $94 \%$. Although only one serotype of BCoV has been identified, the cross-neutralization test using the 66/H antisera showed that the antibody titer against Japan G4 lineage was lower than Japan G2 and G3 lineages [10]. BCoV vaccination might support the development of Japan G4 lineage and decline of G2 and G3 lineages. Thus, genetic information about recent strains may help in the development of the most appropriate vaccine.

This study covered only two areas (Tokai and Kyushu) of Japan, which is geographically divided into eight areas. The movement 
(a)

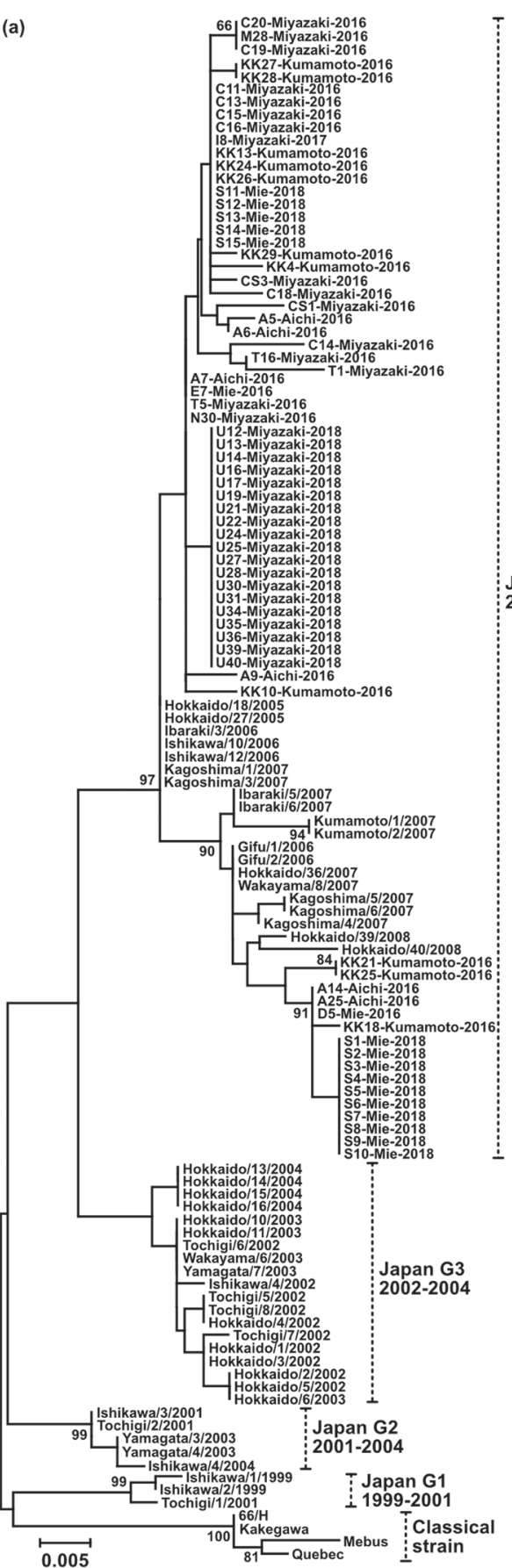

(b)

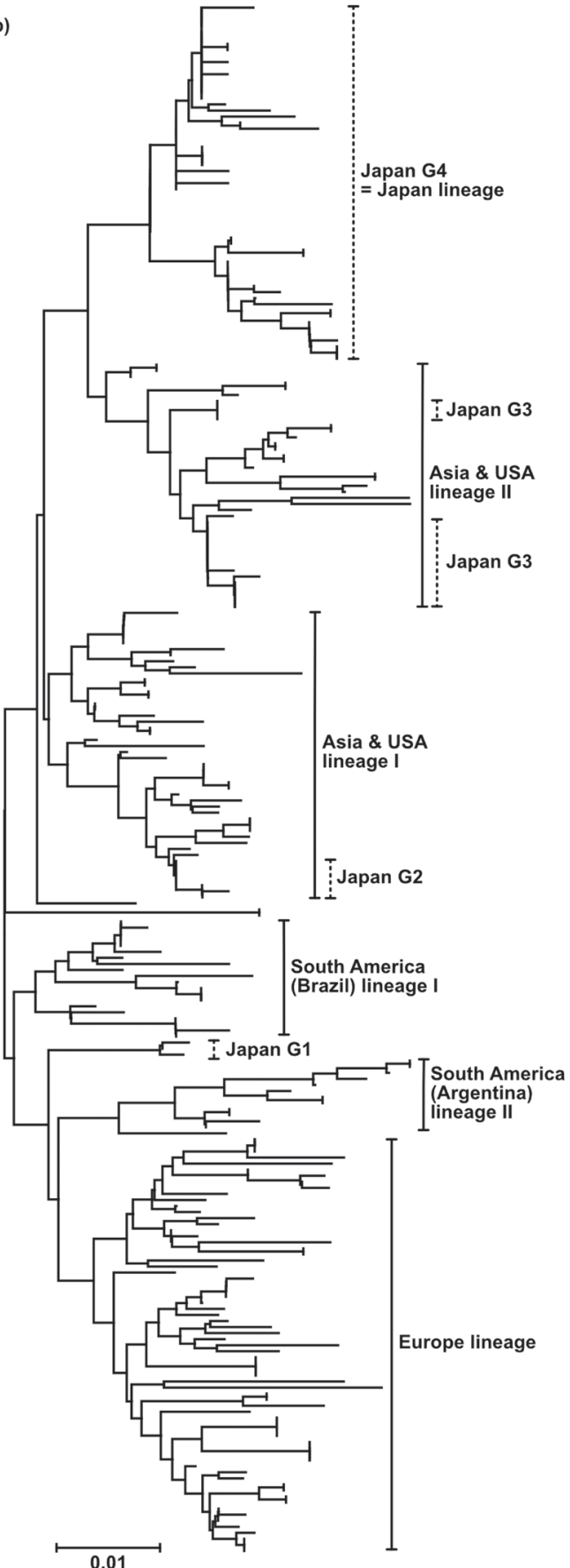

Fig. 2. Phylogenetic analyses of the partial sequences of the BCoV S gene. The analyses involved the polymorphic region of the BCoV S gene at the nucleotide level. The gene corresponded to positions 25,006-25,416 of the Kakegawa strain [9]. The scale bars indicate the number of substitutions per site. (a) Sixty-nine strains identified in this study are connected as "name of strain", "isolated prefecture", and "isolated year" by hyphens (Ex. C20-Miyazaki-2016). On the other hand, the sequences retrieved from GenBank are connected as "isolated prefecture", "name of strains", and "isolated year" by slashes (Ex. Tochigi/1/2001). Bootstrap values of more than $50 \%$ (1,000 replicates) are shown next to the branches. (b) Eighty-six strains identified in Japan from 1999 to 2018 and 170 strains identified throughout the world were involved in the phylogenetic analysis.

of live cattle is very active throughout Japan. Therefore, we think the results reflected not only the circumstances in a few regions but also throughout Japan. However, further studies are required to identify the circumstance of BCoV infection in Japan more accurately. We have few evidences to suggest why Japan G4 has expanded over the last 15 years and why G1-3 went extinct in Japan. One simple theory is that Japan G4 might amplify and spread in cattle easier than G1-3. We successfully isolated six strains classified as Japan G4 (no data shown). Therefore, we will try to verify this hypothesis in the future. 
In conclusion, the findings of this study indicate that $\mathrm{BCoV}$ is an important pathogen in calves with BRD in Japan. Furthermore, the virus might have evolved uniquely in Japan over the last 20 years. Genetic information about recent strains is important for the development of the most appropriate vaccine and to understand viral evolution. To date, there is not enough information available about this virus throughout the world. Therefore, further studies are required to identify the importance and evolution of this virus.

ACKNOWLEDGMENTS. We thank several of our local clinical veterinarians for collecting the nasal swab samples. The Program to Disseminate Tenure Tracking System from the Ministry of Education, Culture, Sports, Science and Technology and JSPS KAKENHI (Grant Number 17K08080) supported the research described in this study.

\section{REFERENCES}

1. Bok, M., Alassia, M., Frank, F., Vega, C. G., Wigdorovitz, A. and Parreño, V. 2018. Passive immunity to control Bovine coronavirus diarrhea in a dairy herd in Argentina. Rev. Argent. Microbiol. 50: 23-30. [Medline]

2. Castells, M., Giannitti, F., Caffarena, R. D., Casaux, M. L., Schild, C., Castells, D., Riet-Correa, F., Victoria, M., Parreño, V. and Colina, R. 2019. Bovine coronavirus in Uruguay: genetic diversity, risk factors and transboundary introductions from neighboring countries. Arch. Virol. 164: 2715-2724. [Medline] [CrossRef]

3. Chouljenko, V. N., Lin, X. Q., Storz, J., Kousoulas, K. G. and Gorbalenya, A. E. 2001. Comparison of genomic and predicted amino acid sequences of respiratory and enteric bovine coronaviruses isolated from the same animal with fatal shipping pneumonia. J. Gen. Virol. 82: $2927-2933$. [Medline] [CrossRef]

4. Diesel, D. A., Lebel, J. L. and Tucker, A. 1991. Pulmonary particle deposition and airway mucociliary clearance in cold-exposed calves. Am. J. Vet. Res. 52: 1665-1671. [Medline]

5. Duan, S. M., Zhao, X. S., Wen, R. F., Huang, J. J., Pi, G. H., Zhang, S. X., Han, J., Bi, S. L., Ruan, L., Dong X. P., SARS Research Team 2003. Stability of SARS coronavirus in human specimens and environment and its sensitivity to heating and UV irradiation. Biomed. Environ. Sci. 16: 246-255. [Medline]

6. Fukutomi, T., Tsunemitsu, H. and Akashi, H. 1999. Detection of bovine coronaviruses from adult cows with epizootic diarrhea and their antigenic and biological diversities. Arch. Virol. 144: 997-1006. [Medline] [CrossRef]

7. Gershwin, L. J., Van Eenennaam, A. L., Anderson, M. L., McEligot, H. A., Shao, M. X., Toaff-Rosenstein, R., Taylor, J. F., Neibergs, H. L., Womack J., Bovine Respiratory Disease Complex Coordinated Agricultural Project Research Team 2015. Single pathogen challenge with agents of the bovine respiratory disease complex. PLoS One 10: e142479. [Medline] [CrossRef]

8. Ijaz, M. K., Brunner, A. H., Sattar, S. A., Nair, R. C. and Johnson-Lussenburg, C. M. 1985. Survival characteristics of airborne human coronavirus 229E. J. Gen. Virol. 66: 2743-2748. [Medline] [CrossRef]

9. Kanno, T., Hatama, S., Ishihara, R. and Uchida, I. 2007. Molecular analysis of the S glycoprotein gene of bovine coronaviruses isolated in Japan from 1999 to 2006. J. Gen. Virol. 88: 1218-1224. [Medline] [CrossRef]

10. Kanno, T., Ishihara, R., Hatama, S. and Uchida, I. 2013. Antigenic variation among recent Japanese isolates of bovine coronaviruses belonging to phylogenetically distinct genetic groups. Arch. Virol. 158: 1047-1053. [Medline] [CrossRef]

11. Kanno, T., Ishihara, R., Hatama, S. and Uchida, I. 2018. A long-term animal experiment indicating persistent infection of bovine coronavirus in cattle. J. Vet. Med. Sci. 80: 1134-1137. [Medline] [CrossRef]

12. Kanno, T., Kamiyoshi, T., Ishihara, R., Hatama, S. and Uchida, I. 2009. Phylogenetic studies of bovine coronaviruses isolated in Japan. J. Vet. Med. Sci. 71: 83-86. [Medline] [CrossRef]

13. Kishimoto, M., Tsuchiaka, S., Rahpaya, S. S., Hasebe, A., Otsu, K., Sugimura, S., Kobayashi, S., Komatsu, N., Nagai, M., Omatsu, T., Naoi, Y., Sano, K., Okazaki-Terashima, S., Oba, M., Katayama, Y., Sato, R., Asai, T. and Mizutani, T. 2017. Development of a one-run real-time PCR detection system for pathogens associated with bovine respiratory disease complex. J. Vet. Med. Sci. 79: 517-523. [Medline] [CrossRef]

14. Kumar, S., Stecher, G. and Tamura, K. 2016. MEGA7: Molecular Evolutionary Genetics Analysis Version 7.0 for Bigger Datasets. Mol. Biol. Evol. 33: 1870-1874. [Medline] [CrossRef]

15. Mekata, H., Minamino, T., Mikurino, Y., Yamamoto, M., Yoshida, A., Nonaka, N. and Horii, Y. 2018. Evaluation of the natural vertical transmission of Theileria orientalis. Vet. Parasitol. 263: 1-4. [Medline] [CrossRef]

16. Mekata, H., Sekiguchi, S., Konnai, S., Kirino, Y., Horii, Y. and Norimine, J. 2015. Horizontal transmission and phylogenetic analysis of bovine leukemia virus in two districts of Miyazaki, Japan. J. Vet. Med. Sci. 77: 1115-1120. [Medline] [CrossRef]

17. Mekata, H., Yamamoto, M., Hamabe, S., Tanaka, H., Omatsu, T., Mizutani, T., Hause, B. M. and Okabayashi, T. 2018. Molecular epidemiological survey and phylogenetic analysis of bovine influenza D virus in Japan. Transbound. Emerg. Dis. 65: e355-e360. [Medline] [CrossRef]

18. Mitra, N., Cernicchiaro, N., Torres, S., Li, F. and Hause, B. M. 2016. Metagenomic characterization of the virome associated with bovine respiratory disease in feedlot cattle identified novel viruses and suggests an etiologic role for influenza D virus. J. Gen. Virol. 97: 1771-1784. [Medline] [CrossRef]

19. O’Neill, R., Mooney, J., Connaghan, E., Furphy, C. and Graham, D. A. 2014. Patterns of detection of respiratory viruses in nasal swabs from calves in Ireland: a retrospective study. Vet. Rec. 175: 351. [Medline] [CrossRef]

20. Sudaryatma, P. E., Mekata, H., Kubo, M., Subangkit, M., Goto, Y. and Okabayashi, T. 2019. Co-infection of epithelial cells established from the upper and lower bovine respiratory tract with bovine respiratory syncytial virus and bacteria. Vet. Microbiol. 235: 80-85. [Medline] [CrossRef]

21. Sudaryatma, P. E., Nakamura, K., Mekata, H., Sekiguchi, S., Kubo, M., Kobayashi, I., Subangkit, M., Goto, Y. and Okabayashi, T. 2018. Bovine respiratory syncytial virus infection enhances Pasteurella multocida adherence on respiratory epithelial cells. Vet. Microbiol. 220: 33-38. [Medline] [CrossRef]

22. Tsunemitsu, H., Yonemichi, H., Hirai, T., Kudo, T., Onoe, S., Mori, K. and Shimizu, M. 1991. Isolation of bovine coronavirus from feces and nasal swabs of calves with diarrhea. J. Vet. Med. Sci. 53: 433-437. [Medline] [CrossRef]

23. Yoo, D. and Deregt, D. 2001. A single amino acid change within antigenic domain II of the spike protein of bovine coronavirus confers resistance to virus neutralization. Clin. Diagn. Lab. Immunol. 8: 297-302. [Medline] [CrossRef]

24. Zhang, M., Hill, J. E., Fernando, C., Alexander, T. W., Timsit, E., van der Meer, F. and Huang, Y. 2019. Respiratory viruses identified in western Canadian beef cattle by metagenomic sequencing and their association with bovine respiratory disease. Transbound. Emerg. Dis. 66: 1379-1386. [Medline] [CrossRef] 